\title{
ESTUDO COMPARATIVO DA SUSCEPTIBILIDADE DE LINHAGENS DE CÉLULAS DIPLÓIDES HUMANAS AO VIRUS DA CITOMEGALIA (VCM) (1)
}

StewIEN, K. E. - Estudo comparativo da susceptibilidade de linhagens de células diplóides humanas ao vírus da citomegalia (VCM). Rev. Saúde pribl., S. Paulo, 5:59-65, 1971.

RESUMo - São apresentados os resultados de um estudo comparativo da susceptibilidade de diversas linhagens de células diplóides humanas (FH, $\mathrm{FH}_{3}, \mathrm{FH}_{4}, \mathrm{FH}_{11}, \mathrm{FH}_{13}, \mathrm{FH}_{14}, \mathrm{FH}_{16}$ ) ao vírus da citomegalia (VCM). Das linhagens referidas, tôdas se mostraram sensiveis aos virus estudados, com exceçāo das linhagens $\mathrm{FH}_{3}$ e $\mathrm{FH}_{16}$; estas vieram mostrar o mesmo grau de susceptibilidade depois de várias sub-culturas, no momento em que o aspecto morfológico da camada celular passou de heterogêneo - células fibroblásticas e epiteliais - a homogêneo - células fibroblásticas.

UNITERMos - Virus citomegálico *; Células diplóides humanas*; Corpúsculos de inclusão*.

\section{INTRODUCAO}

Com o desenvolvimento de métodos de diagnóstico, baseados em estudos citoló$\operatorname{gicos}^{4,10}$ e 21 e de técnicas de isolamento do agente etiológico, a partir de diferentes materiais ${ }^{12,14} \mathrm{e}^{18}$, era de se esperar um progresso rápido para um conhecimento melhor da citomegalia, a exemplo do que ocorreu com a maioria das demais viroses humanas. Entretanto, os estudos de investigação sôbre a citomegalia tiveram um desenvolvimento moderado, isto certamente devido aos atributos peculiares do seu agente etiológico e das relações dêste com o hospedeiro. Assim, sòmente uma série de estudos sôbre as propriedades incomuns do vírus da citobegalia (VCM) e das suas relações suigeneris com as células hospedeiras, permitirá avaliar com segurança cada vez maior os resultados dos diagnósticos clínico-laboratoriais, bem como eliminar dificuldades práticas na elucidação do seu comportamento como agente etiológico. Estes estudos são revestidos de importância, pois, ao contrário do que anteriormente se pensava, as infecçöes com o vírus da citomegalia são freqüentes, tanto em crianças, quanto em adultos.

Recebido para publicação em 16-3-1971.

(1) Trabalho realizado no Departamento de Virologia do Instituto de Higiene, da Universidade de Hamburgo, República Federal da Alemanha.

(2) Do Departamento de Microbiologia e Imunologia do Instituto de Ciências Biomédicas da USP - Av. Dr. Arnaldo, 715, São Paulo, SP - Brasil. 
STEWIEN, K. E. - Estudo comparativo da susceptibllidade de linhagens de células diplóides humanas ao vírus da cintomegalia (VCM). Rev. Saúde públ., S. Paulo, 5:59-65, 1971.

Uma das características mais peculiares do vírus da citomegalia, também denominado vírus das glândulas salivares (vGs), refere-se à sua proliferação que, in vitro, ocorre em células fibroblásticas $\mathrm{e}$ in vivo, preferencialmente em células epiteliais ${ }^{15}$ e 18 . Em conseqüência, o isolamento dêste agente infeccioso está limitado às culturas de fibroblastos. Assim, tanto para $o$ isolamento e a multiplicação, quanto para as provas de neutralização ${ }^{1,2}, 6,12,15,16,19 \mathrm{e} 20$, têm sido utilizadas, quase que exclusivamente, culturas de células diplóides de feto humano, que oferecem diversas vantagens sôbre as demais culturas de fibroblastos conhecidas 7 e 8. As culturas de células diplóides humanas, além de serem essencialmente constituidas de fibroblastos, mantêm inalterado o número de cromossomas durante cêrca de 50 passagens $( \pm 10)$.

0 presente trabalho apresenta os resultados de um estudo comparativo da susceptibilidade de diversas linhagens de células diplóides humanas a 3 estirpes do vírus da citomegalia e a outros vírus, para efeito de comparação.

\section{MATERIAL E METODOS}

Culturas de células diplóides. Para a multiplicação dos vírus estudados, foram utilizadas sub-culturas de linhagens de células diplóides humanas. Cada linhagem provém de um feto (pele e músculos), submetido a tripsinizações sucessivas, segundo a técnica de FERnandes ${ }^{3}$. As células eram cultivadas em garrafas de Roux, sendo em cada semana realizada uma passagem, utilizando-se como meio dispersante uma solução de tripsina a $0,2 \%$, em salina tamponada, sem ions de $\mathrm{Ca}$ e Mg. A partir destas passagens, foram preparadas, para as devidas inoculações, sub-culturas em garrafas, em tubos e sôbre lamínulas contidas em tubos de cultivo. Estas últimas, após um período estacionário de incubação de cêrca de $18 \mathrm{~h}$, eram colocadas num tambor de posição vertical, com movimento giratório, permanecendo ali até a confluência das células em camada unicelular. Antes da inoculação, o meio de crescimento (Eagle MEM $+10 \%$ de sôro de vitelo) era eliminado e após uma lavagem com êste meio, mas destituído do sồro, adicionava-se o meio de manutenção (Eagle MEM + $1 \%$ de sôro fetal de vitelo). As garrafas, os tubos e as culturas sôbre lamínulas recebiam, respectivamente, 15 , 1 e $4 \mathrm{ml}$ de meio de manutenção. Todos os meios continham 5 microgramas de Gentamycin (Merck).

Virus. Foram utilizadas 3 estirpes do vírus da citomegalia, das quais 2 eram procedentes de Hamburgo (Rep. Fed. da Alemanha), HH-2568 (4. ${ }^{a}$ pass.) e HH-3087 (2. ${ }^{a}$ pass.), e uma era procedente de St. Gallen (Suiça), SG-424 (19. ${ }^{a}$ pass.). Foram também incluídos no presente estudo o vírus Herpes simplex, os Adenovírus dos tipos 1 e 4 e as estirpes atenuadas de Sabin dos tipos 1, 2 e 3. Os inóculos dêstes vírus consistiam de suspensões de culturas de células diplóides da linhagem $\mathrm{FH}_{\mathbf{1}}$ mostrando um efeito citopático generalizado $(4+)$. Antes de sua inoculação em sub-culturas das diferentes linhagens, as estirpes do vírus da citomegalia, mantidas em estoque a $-70^{\circ} \mathrm{C}$, eram prèviamente passadas em uma cultura da linhagem $\mathrm{FH}_{1}$. A suspensão e a inoculação dos vírus da citomegalia eram feitas mediante a utilização de seringas de $10 \mathrm{ml}$, para uma remoção melhor das células aderentes e a ruptura de tôdas as células infectadas. Após um período de $3 \mathrm{~h}$ de incubação, o meio de manutenção era uma vez trocado, evitando-se con isto o aparecimento de efeitos citotóxicos, ocasionados pela presença de fragmentos celulares nos inóculos.

Preparação das culturas para os estudos histológicos. As culturas destinadas ao estudo histológico foram fixadas em solução de Carnoy e coradas com hematoxilina e eosina. As culturas (laminulas) eram fixadas e coradas nos próprios 
STEWIEN, K. E. - Estudo comparativo da susceptlbilídade de linhagens de células díplóldes humanas ao virus da cintomegalla (VCM). Rev. Saride puibl., S. Paulo, 5:59-65, 1971.

tubos, sendo, a seguir, montadas sôbre lâminas, para o exame microscópico. Culturas não inoculadas foram paralelamente preparadas, como contrôles.

\section{RESULTADOS}

Na Tabela estão contidos, em resumo, os resultados das experiências sôbre a multiplicação dos vírus da citomegalia (vcM) e dos outros vírus estudados, em diversas sub-culturas das 7 linhagens de células diplóides humanas examinadas. Nota-se na Tabela, que as sub-culturas de baixa passagem das linhagens $\mathrm{FH}_{3}$ e $\mathrm{FH}_{18}$, inoculadas com as estirpes $\mathrm{HH}-2568$ e HH-3087, não acusaram efeito citopático. 0 período de observação foi de 5 a 6 semanas. Culturas fixadas e coradas com hematoxilina e eosina não revelaram corpúsculos de inclusão, ao exame microscópico. Entretanto, sub-culturas das mesmas linhagens evidenciaram um efeito citopático característico ao vírus da citomegalia, quando inoculadas com a estirpe
SG-424 (19.^ pass.). Este efeito foi observado no terceiro dia de incubaçáo, apenas um dia após o aparecimento de efeito citopático nas sub-culturas das outras linhagens estudadas.

Verificada a ausência de susceptibilidade nas linhagens $\mathrm{FH}_{3}$ e $\mathrm{FH}_{16}$, levantou-se a hipótese de que as células dos fetos e, conseqüentemente, as das linhagens, estivessem infectadas de modo latente com o vírus da citomegalia. Com a finalidade de confirmar esta hipótese, sub-culturas das mesmas linhagens foram tripsinizadas, as células suspensas em pequena quantidade de meio de manutenção e destruídas num homogeneizador a 16.000 r.p.m. Após centrifugados os fragmentos celulares, o sobrenadante foi então inoculado em sub-culturas $\mathrm{FH}_{1}$ e $\mathrm{FH}_{4}$, conhecidas como sensíveis ao vírus da citomegalia. As garrafas receberam uma quantidade de $10 \mathrm{ml}$ do inóculo e os tubos (com as culturas em lamínulas), receberam um total de $4 \mathrm{ml}$. As culturas foram incubadas a $36^{\circ} \mathrm{C}$, durante um

T A B E L A

Susceptibilldade de sete linhagens de células diploides humanas ao virus da citomegalla (VCM) e a outros virus

\begin{tabular}{|c|c|c|c|c|c|c|c|}
\hline \multirow{2}{*}{ Linhagens } & \multirow{2}{*}{$\begin{array}{l}\text { N.o da sub-cul- } \\
\text { tura inoculada }\end{array}$} & \multicolumn{6}{|c|}{ Virus } \\
\hline & & HHL-2568 & $\begin{array}{l}\text { Citomegalis } \\
\text { HH-3087 }\end{array}$ & SG-424 & $\begin{array}{l}\text { Herpes } \\
\text { simplex }\end{array}$ & $\begin{array}{l}\text { Adeno- } \\
\text { virus }\end{array}$ & $\begin{array}{c}\text { Sabin } \\
1,2 \text { e } 3\end{array}$ \\
\hline \multicolumn{8}{|c|}{. } \\
\hline 1. $\mathrm{FH}_{1}$ & $3,6,20$ e 27 & + & + & + & + & $\mathbf{N}$ & $\mathbf{N}$ \\
\hline \multirow[t]{2}{*}{ 2. $\mathrm{FH}_{2}$} & $3,6,7$ & - & - & + & + & + & + \\
\hline & 8,10 & + & + & + & + & + & + \\
\hline 3. $\mathbf{F H}_{4}$ & $2,3,18$ & + & + & + & + & $\mathbf{N}$ & $\mathbf{N}$ \\
\hline 4. $\mathrm{FH}_{11}$ & 2,11 & + & + & + & $\mathbf{N}$ & $\mathbf{N}$ & $\mathbf{N}$ \\
\hline 5. $F_{12}$ & $\mathbf{3}, 9$ & + & + & $\mathbf{N}$ & $\mathbf{N}$ & $\mathbf{N}$ & $\mathbf{N}$ \\
\hline 6. FH' & 2,11 & + & + & + & + & $\mathbf{N}$ & $\mathbf{N}$ \\
\hline \multirow[t]{2}{*}{ 7. $\mathrm{FH}_{16}$} & 2,3 & - & - & + & + & + & + \\
\hline & 4,9 & + & + & + & + & $\mathbf{N}$ & $\mathbf{N}$ \\
\hline
\end{tabular}

+ - Presença de efelto citopático e de corpúsculos de inclusáo

- - Ausencia de efeito citopático e de corpúsculos de inclusăo

N - Exame não realizado 
STEWIEN, K. E. - Estudo comparativo da susceptibilidade de linhagens de células diplóides humanas ao virus da cintomegalia (VCM). Rev. Saúde públ., S. Paulo, 5:59-65, 1971.

período de 5 a 6 semanas, com trocas semanais do meio de manutenção. Nêste periodo, entretanto, não houve manifestação de efeito citopático nas culturas inoculadas, nem foi possível encontrar corpúsculos de inclusão no interior das células fixadas e coradas, ao exame microscópico (Figura 1).

Foi, então, realizado um estudo sôbre o caráter morfológico das linhagens de células diplóides humanas. Sub-culturas de uma série de passagens (ver Tabela) foram fixadas e coradas para o exame microscópico. De um modo geral, as linhagens examinadas apresentaram um aspecto morfológico uniforme, com camadas celulares formadas essencialmente por fibroblastos, exceto as linhagens $\mathrm{FH}_{3}$ e $\mathrm{FH}_{16}$, cujas primeiras sub-culturas mostraram camadas heterogêneas de células

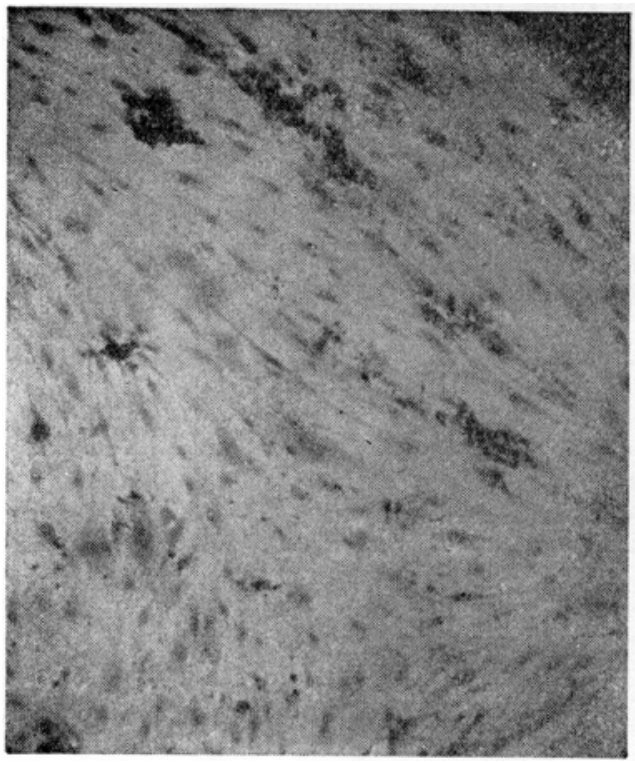

Fig. 1 - Cultura de células diplóides humanas da linhagem $\mathrm{FH}_{1}$, inoculada com uma suspenção de células (prèviamente destruías) da linhagem $\mathrm{FH}_{3}$ (6.a sub-cultura), após um perlodo de incubação de 6 semanas. Observam-se sòmente alguns efeitos citótóxicos. Coloração: hematoxilina e eosina. $90 \mathrm{x}$. fibroblásticas e epiteliais. Se bem que a proporção de fibroblastos fôsse predominante, a quantidade de células epiteliais nas camadas era considerável. Entretanto, alterou-se $\mathrm{o}$ aspecto morfológico das camadas celulares na linhagem $\mathrm{FH}_{3}$, a partir da $8 .^{\mathrm{a}}$ sub-cultura, e na linhagem $\mathrm{FH}_{16}$, a partir da $4 .^{\mathrm{a}}$ sub-cultura, tornando-se homogêneo, como nas outras linhagens examinadas. Simultâneamente, as duas linhagens manifestaram um efeito citopático característico ao vírus da citomegalia, quando inoculadas com as estirpes de baixa passagem HH-2568 e HH-3087. O aparecimento dos primeiros focos de infecção se deu nas culturas inoculadas com a estirpe HH-2568 no $4 .^{\circ}$ dia de incubação e nas culturas inoculadas com a estirpe HH-3087, no $6 .^{\circ}$ dia de incubação. Observou-se um aumento gradativo do número e do tamanho dos focos de infecção até a sua confluência

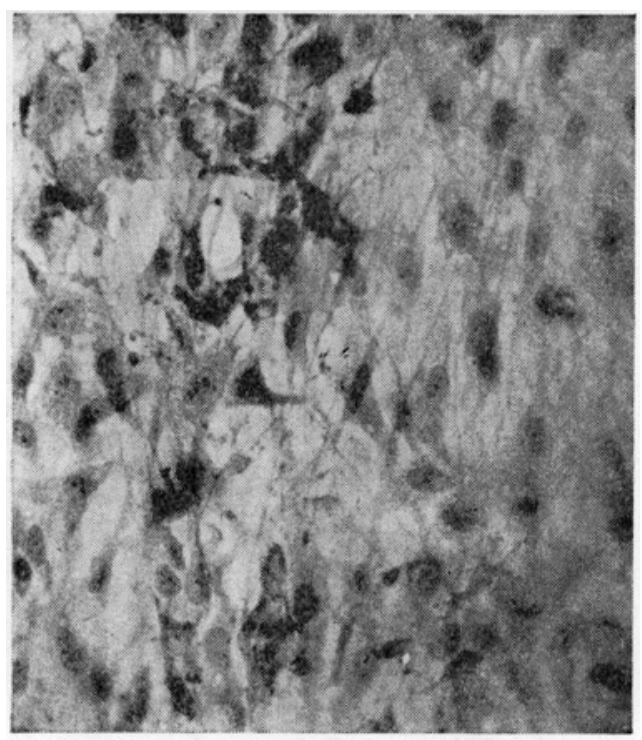

Fig. 2 - Cultura de células diplóides humanas da linhagem $\mathrm{FH}_{3}$ (3.a passagem). Nota-se o aspecto morfológico heterogêneo da camada celular. Coloração: hematoxilina e eosina. $360 \mathrm{X}$. 
STEWIEN, K. E. - Estudo comparativo da susceptibilidade de linhagens de células diploides humanas ao virus da cintomegalla (VCM). Rev. Saúde públ., S. Paulo, 5:59-65, 1971.

total, que se deu, respectivamente, no $12 .^{\circ}$ e no $140^{\circ}$ dia de incubação. Preparaçōes das culturas revelaram, ao microscópio, nos núcleos das células infectadas as inclusões características do vírus da citomegalia (Figura 3). Inoculadas com a estirpe SG-424 e com os outros vírus (Tabela), as linhagens $\mathrm{FH}_{3}$ e $\mathrm{FH}_{16}$ manifestaram efeito citopático após 24 horas de incubação, a exemplo das demais linhagens examinadas.

Foi determinado o título infeccioso da estirpe $\mathrm{HH}-2568$ nas linhagens $\mathrm{FH}_{3}\left(8 .^{\mathrm{a}}\right.$ sub-cultura) e $\mathrm{FH}_{1}$ (27.9 sub-cultura). 0 inóculo consistiu de uma suspensão de células infectadas com $\mathrm{HH}-2568$, obtida de uma sub-cultura $\mathrm{FH}_{3}\left(8 .^{\mathrm{a}}\right.$ pass.) apresentando um efeito citopático total. Culturas em tubos foram inoculadas com quantidades de $0,2 \mathrm{ml}$ do inóculo não diluído e das diluições $10^{-1}$ até $10^{-5}$, empregando-se 3 tubos por diluição. Um efeito citopático foi verificado nos 3 tubos das diluiçōes $10^{\circ}, 10^{-1}$ e $10^{-2}$, no

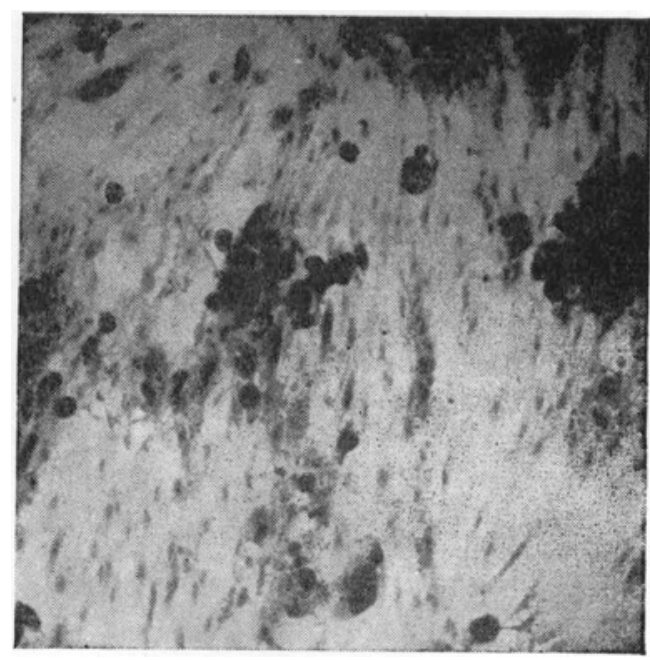

Fig. 3 - Aspecto de uma cultura da linhagem FH, (8.a passagem), Infectada com a estirpe HH-2568 do virus da citomegalia, após um perlodo de incubação de 14 dias. Observam-se diversas celulas apresentando corpúsculos de inclusão, envolvidos por um halo claro. Coloração: hematoxilina e eosina. $360 \mathrm{X}$.

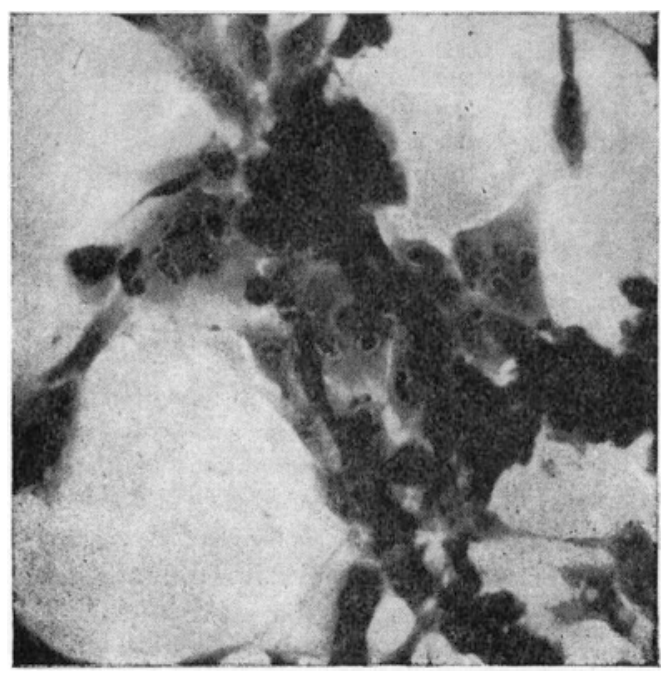

Fig. 4 - Aspecto de uma cultura da linhagem FH, (8.4 passagem), infectada com Adenovirus do tipo 4. Observam-se diversos focos de infecção apresentando células arredondadas. Coloração: hematoxilina e eosina. $90 \mathrm{X}$.

quarto dia de incubação, sendo que na diluição $10^{-3}$, a última diluição positiva, o efeito citopático apareceu no oitavo dia de incubação. Segundo a técnica de Reed e Muench, o título final da estirpe HH-2568 foi de $10^{3,5}$ e $10^{3,25}$, respectivamente, nas culturas $\mathrm{FH}_{1}$ e $\mathrm{FH}_{3}$.

\section{DISCUSSAO}

A identificação sorológica do vírus da citomegalia enfrenta dois problemas fundamentais. $\mathbf{O}$ primeiro refere-se a diversas dificuldades no preparo dos soros hiperimunes de referência $e, o$ segundo, diz respeito à obtenção de quantidades suficientes de vírus para as provas sorológicas, que sòmente são obtidas após uma série de passagens em culturas de fibroblastos. Devido a estas dificuldades, o isolamento do vírus, seguida da pesquisa ao microscópio dos corpúsculos de inclusão, é para o diagnóstico da citomegalia o método da escôlha. Consideran- 
STEWIEN, K. E. - Estudo comparativo da susceptibllidade de linhagens de células diplótdes humanas ao virus da cintomegalia (VCM). Rev. Saúde pribl., S. Paulo, 5:59-65, 1971.

do que os doentes apresentam viremia de período relativamente longo 5,0 e 13 , 0 isolamento a partir de amostras de urina oferece, na prática, boa margem de exito ${ }^{11,17}$.

Diversos estudos mostraram que in vitro as células susceptíveis são os fibroblastos, ao contrário do que foi verificado in vivo, onde o vírus da citomegalia prefere multiplicar-se nas células epiteliais. Tentativas no sentido de propagar êste vírus em culturas primárias de rim de macaco rhesus (RMK) e de âmnio humano, bem como em células HeLa, deram resultados negativos ${ }^{15}$ e 18 .

Neste estudo foram observadas duas linhagens de células diplóides humanas que não foram sensíveis a duas estirpes recém-isoladas (HH-2568 e HH-3087) do vírus da citomegalia. Estas linhagens $\left(\mathrm{FH}_{3}\right.$ e $\left.\mathrm{FH}_{1 \mathrm{c}}\right)$, entretanto, foram susceptíveis a uma estirpe do virus da citomegalia de número elevado de passagens (SG-424, 19 pass.) e aos demais vírus inoculados (ver Tabela). Com o intuito de elucidar êste fenomeno, uma série sucessiva de sub-culturas das duas linhagens e das outras linhagens estudadas, foi preparada e inoculada com as 3 estirpes do vírus da citomegalia e com outros vírus. A suspeita inicial de que a ausência de susceptibilidade das linhagens $\mathrm{FH}_{3}$ e $\mathrm{FH}_{16}$ pudesse ser devida a uma infecção latente com um vírus da citomegalia, não teve confirmação, pois os inóculos preparados a partir de suas células não produziram efeito citopático nas culturas de células diplóides, conhecidas como sensíveis ao vírus da citomegalia.

Um exame microscópico da série de sub-culturas preparadas, entretanto, permitiu descobrir diferenças significativas quanto ao aspecto morfológico das camadas unicelulares. As linhagens $\mathrm{FH}_{3}$ e $\mathrm{FH}_{16}$ mostraram, em suas primeiras subculturas, um aspecto morfológico heterogêneo, com células fibroblásticas e epiteliais, ao contrário das demais linhagens, que desde a primeira passagem apresen- taram um aspecto homogêneo de fibroblastos. A partir do momento em que as linhagens $\mathrm{FH}_{3}$ e $\mathrm{FH}_{16}$ deixaram de mostrar camadas unicelulares de aspecto heterogêneo, passando para homogêneo, evidenciaram susceptibilidade também aos vírus de baixa passagem, $\mathrm{HH}-2568$ e $\mathrm{HH}$ 3087.

Os resultados dêste trabalho permitem concluir, pois, que sòmente culturas mostrando camadas celulares de aspecto essencialmente fibroblástico se prestam para o isolamento do vírus da citomegalia.

STEWIEN, K. E. [Comparative study of the susceptibility of human diploid cell strains to the cytomegalovirus]. Rev. Saride públ., S. Paulo, 5:59-65, 1971.

SUMMARY - A comparative study of the susceptibility of different strains of human diploid cells $\left(\mathrm{FH}_{1}, \mathrm{FH}_{3}, \mathrm{FH}_{4}, \mathrm{FH}_{11}\right.$, $\mathrm{FH}_{13}, \mathrm{FH}_{14}, \mathrm{FH}_{15}$ ) to cytomegalovirus disclosed a relation between the capacity of growing and producing a consistent cytophatic effect of human cytomegalovirus strains and the homogeneous characteristics of the tissue cultures. The cell strains $\mathrm{FH}_{3}$ and $\mathrm{FH}_{18}$ were insusceptible when fibroblasts and epithelial cells were present in the same culture. After a certain number of passages, when the fibroblastic characteristics of cells in the cultures was established, the cytophatic effect could be consistently observed.

UNITERMs - Cytomegalovirus *; Human diploid strains*; Bodies, inclusion *.

\section{A GRADE C I ENTOS}

Ao chefe do Departamento de Virilogia do Instituto de Higiene de Hamburgo, República Federal da Alemanha, Prof. Dr. H. Lennartz, que nos possibilitou realizar êste trabalho em seus laboratórios; á Dra. K. Fischer pelas proveitosas sugestões prestadas durante a elaboraçåo da parte experimental da pesquisa; aos Profs. Drs. Dacio de Almeida Christovão e José Alberto Neves Candeias pelas valiosas sugestões oferecidas na revisão do texto; ao Dr. Dino G. B. Patolli, pelas excelentes microfotografias. 
STEWIEN, K. E. - Estudo comparativo da susceptibllidade de linhagens de células diplóides humanas ao virus da cintomegalia (VCM). Rev. Saúde públ., S. Paulo, 5:59-65, 1971.

\section{REFERENCIAS BIBLIOGRAFICAS}

1. DIOSI, P. et al. - Cytomegalovirus infection associated with pregnancy. Lancet, 2:1063-6, 1967.

2. DIOSI, P, et al. - Cytomegalovirus type cytophatic changes in spontaneously degenerating human embrionic cell cultures. Nature, 214:419-20, 1967.

3. FERNANDES, M. V. - The development of a human amnion strain of cells. Tex. Rep. Biol. Med., 16:48-58, 1958.

4. FETTERMAN, G. H. - New laboratory aid in clinical diagnosis of inclusion disease of infancy. Amer. J. clin. Path. 22:424, 1952.

5. HANSHAW, J. B. \& WELLER, T. H. Urinary excretion of cytomegaloviruses by children with generalized neoplastic disease: correlation with clinical and histophatologic observations. J. Pedriat. 58: 305-11, 1961.

6. HANSHAW, J. B. et al. - Acquired cytomegalovirus infection: association with hepatomegalia and abnormal liverfunction tests. New Eng. J. Med., 272: 602-9, 1965.

7. HAYFLICK, L. \& MOORHEAD, P. S. The serial cultivation of human diploid cell strains. Exp. Cell Res., 25:585-621 1961.

8. HAYFLICK, L. - A comparison of primary monkey kidney, heteroploid cell lines and human diploid cell strains for human virus vaccine preparation. Amer. Rev. resp. Dis. 88:387-93, 1963.

9. KLUGE, R. C. et al. - Cytomegalic inclusion disease of newborn: report of case with persistent viruria. Pediatrics, $25: 35-9,1960$.

10. MERCER, R, D. et al. - Clinical diagnosis of generalized cytomegallc inclusion disease, Pedriatrics, 11:502-14, 1953.

11. NUMAZAKI, $Y$. et al. - Primary infection with human cytomegalovirus: virus iso- lation from healthy infants and pregnant women. Amer. J. Epidem., 91:410-17, 1970.

12. ROWE, W. P. et al. - Cytomegalic agent resembling human salivary gland virus recovered from tissue cultures of human adenoids. Proc. Soc. exp. Biol., New York $92: 418-24,1956$.

13. ROWE, W. P. et al. - Detection of human salivary gland virus in mouth and urine of children. Amer, J. Hyg., 67: 57-65, 1958.

14. SMITH, M. G. - Propagation in tissue cultures of cytophatogenic virus from human salivary gland virus (SGV) disease. Proc. Soc. exp. Biol., New York, 92:42430, 1956.

15. STERN, H. et al. - Isolation of cytomegalovirus in an infant with angiosarcoma. Arch. Dis. Childh. 38:626-31, 1963.

16. STERN, H. \& ELEK, S. P. - The incidence of infection with cytomegalovirus in a normal population. A serological study in greated London. J. Hyg., London, 63:79-87, 1965.

17. STERN, H. - Isolation of cytomegalovirus and clinical manifestation of infection at different ages. Brit. Med. J., 1:655$69,1958$.

18. WELLER, T. $H$. et al. - Isolation of intranuclear inclusion producing agents from infants with illnesses resembling cytomegalic inclusion disease. Proc. Soc. exp. Biol., New York, 94:4-12, 1957.

19. WELLER, T. H., HANSHAW, J. B. \& SCOTT, D. E. - Serologic differentiation of virus responsible for cytomegalic inclusion disease. Virology, 12:130-2, 1960.

20. WELLER, T. H. \& HANSHAW, J. B. Virologic and clinical observation on cytomegalic inclusion disease. New Eng. J. Med., 266:1233-44, 1962.

21. WYATT, J. P. et al. - Generalized cytomegalic inclusion disease. J. Pediat., 36: 271-94, 1950. 